\title{
A Comparative Study of Technological Impact on Mushroom Industry in Sri Lanka: A Review
}

\author{
Sanath Gamage, Shoji Ohga \\ Department of Agro-Environmental Sciences, Faculty of Agriculture, Kyushu University, Fukuoka, Japan \\ Email: ohga@forest.kyushu-u.ac.jp, gamage.wgsb@gmail.com
}

How to cite this paper: Gamage, S. and Ohga, S. (2018) A Comparative Study of Technological Impact on Mushroom Industry in Sri Lanka: A Review. Advances in Microbiology, 8, 665-686. https://doi.org/10.4236/aim.2018.88045

Received: June 18, 2018

Accepted: August 28, 2018

Published: August 31, 2018

Copyright $\odot 2018$ by authors and Scientific Research Publishing Inc. This work is licensed under the Creative Commons Attribution International License (CC BY 4.0).

http://creativecommons.org/licenses/by/4.0/

(c) (i) Open Access

\begin{abstract}
The present status of technological implementation for mushroom industry in Sri Lanka is expressed along this paper. It has been comparatively discussed with entire Japanese mushroom industry. Sri Lanka is a developing country located in south Asia. Almost all the mushroom cultivators in the country are growing Pleurotus ostreatus, Calocybe indica and Volvariella volvacea. These species are most preferred because they are not difficult to cultivate using the low cost cultivation method being practiced in the country. Mushroom cultivators are selling their product at prices ranging from LKR 240 (1.47) to LKR 430 (USD 2.63) per kg in 2017. Mushroom cultivation is not that popular in Sri Lanka. This may be, partly, attributed to lack of know-how, technological barrier and awareness on the economic, nutritive and medicinal benefits of cultivated mushrooms. Some of the major supermarkets do sell locally cultivated P. ostreatus and, Agaricus bisporus and Lentinula edodes mushrooms which are imported from the Republic of China and Thailand. At present, there are few private and government institutions which produce spawn and offer knowledge to the farmers. Their programs have been mainly focused on mushroom cultivation as a woman's household business; but the industry should be developed towards large scale commercial mushroom cultivation as well. This study is focused on main steps of mushroom production with some discussion and suggestion for increase production efficiency through technological advancement.
\end{abstract}

\section{Keywords}

Wild Mushroom, Commercial Mushroom Production, Japan, Sri Lanka, Technological Implementation

\section{Introduction}

The mushroom belongs to class Basidiomycetes which are fleshly saprophyte 
fungi found growing on damp rotten wood trunk of trees, decaying organic matter and damp soil rich in organic substances. The word "mushroom" also refers only to the fruit body of certain fungi. They are heterotrophs and could not use solar energy as green plants. Photosynthesis cannot be done because there is no chlorophyll include in fungi cell. They use chemical energy of absorbed nutrients from outer sources for metabolism [1].

Sri Lanka is a developing country located in south Asia. Most of people in Sri Lanka have known and used wild edible mushrooms as food since time immemorial. These wild edible mushrooms are seasonal, available only during the rainy season. After a long period, it has been observed and learned how to cultivate mushrooms. Presently, fungi cultivation develops with the advance of science and technology. Mushrooms have become popular throughout the world. It is considered as one of the important food items rich with medicinal values since ancient time and its consumption continues to increase for its significant role in human health, nutrition and diseases [2]. In Sri Lanka, the local demand for mushrooms is also steadily increasing [3].

Mushrooms have ability to convert less valuable compost media into edible food source and those are eaten as meat substitutes and flavoring. In general edible mushrooms are low in fat and calories, rich in vitamin B and C, and contain more protein than any other food of plant origin. Those are also a good source of mineral nutrients [4]. Some examples of nutritive nutraceuticals or functional food ingredients are dietary fiber, poly-unsaturated fatty acids (PUFA, fish oil), proteins, peptides, amino acids, keto acids, minerals, antioxidative vitamins and other antioxidants (glutathione, selenium, etc.) [5] [6]. The medicinal properties have been reported in some sort of mushrooms include Ophiocordyceps sinensis, Cordyceps militaris, Ganoderma lucidum, Lentinula edodes, Antrodia cinnamomea, Grifola frondosa and Agaricus blazei. Some of the most recently isolated and identified compounds extracted from the edible and medicinal mushrooms have shown pharmacological actions include hypocholesterolemic [7], antitumor and antioxidant [8], antifungal [9], antiviral, immunomodulatory, antibacterial, antiparasitic, hepatoprotective and antidiabetic properties [10]. Those extracts also act against some diseases, specially cardiovascular and inflammatory diseases [9] [11] [12], and also have an ability to maintain the blood cholesterol at the optimum level.

Currently, high bio-fuel prices have caused an increasing in food prices and food scarcity in many countries. Malnutrition in terms of protein deficiency is becoming a major hazard in developing countries. Mushrooms with their flavor, texture, nutritional value and high productivity per unit area have been identified as an excellent food source to alleviate malnutrition in developing countries [13]. The small scale mushroom production represents an opportunity for farming community interested in an additional income and is an ideal option specifically for those without much land [14]. With mushroom cultivation, ordinary people from communal areas, periurban dwellers and commercial farmers can earn considerable income and employ many others. 
In Japan, the total production of edible mushrooms in 2009 was 461,107 tons and added 249.9 billion yen (3.01 billion US dollars, 1 dollar $=83$ Yen) to the GDP. F. velutipes (Enokitake) production has been steadily increasing since 1970 and was 138,501 tons in 2009. Production in 2009 has been increased in $5.6 \%$ compared to 2008 because of the average yields per bottle have been increased with considerable development of cultivation techniques. About $44 \%$ of the total H. marmoreus (Bunashimeji) production of 110,741 tons in 2009 was produced by two large mushroom companies, Hokuto and Yukiguni. Total production of (L. edodes) Shitake (based on fresh Shiitake and dried Shiitake converted to fresh weight) was 101,392 tons in 2009. G. frondosa (Maitake) is mainly cultivated using plastic bags and sawdust substrate. P. eryngii (King oyster) is the most recently introduced fungal species to Japan. Production has increased rapidly since 2000 and 37,223 tons were produced in 2009 compared with 6734 tons in 2000. P. nameko (Nameko) and P. ostreatus (Hiratake) are other popular mushroom type in Japan. Matsutake (Tricholoma matsutake) is a wild mushroom harvested from $P$. densiflora forests in Japan. The retail price is in the region of US\$ 600 per $\mathrm{kg}$ but it can reach US\$ 1800 per $\mathrm{kg}$ in a lean year. The yield in the past decade has reduced to between 30 to 100 tons per year. The main reasons for the decrease in the Matsutake harvest are reductions of forest management practices that favor Matsutake fruiting and a decline in $P$. densiflora forests due to Pine wilt disease as a result of nematode infection [15].

Mushroom farming also can play an important role in managing farm organic waste [14]. However, Sri Lanka has high potential for widespread production because of availability of abundant materials from agriculture wastes that could be used for mushroom production. In Sri Lanka, mushroom cultivation is highly rewarding because of the prevailing climatic conditions. All that is needed is to popularize this crop and build capacity in the art of mushroom farming. Although the history of the world mushroom cultivation goes back to thousands years the commercial mushroom cultivation in Sri Lanka was started in the middle of 1980's with the cultivation of Oyster mushroom. The abundance of imported mushrooms in retail shops and supermarkets in Sri Lanka reflects the need for a continuous supply of good quality, locally grown mushrooms. However, compared to other countries, technological improvements of mushroom cultivation are not satisfactory in Sri Lanka [3]. In spite of the potential of mushroom growing in improving livelihoods of people and the ease of accessibility of materials for production, mushroom cultivation in Sri Lanka is still in its infancy because of lack of technological knowhow of the efficient production. The purpose of this paper is to provide useful baseline information for any upcoming initiatives aimed at promoting commercial mushroom cultivation in Sri Lanka.

\section{Methodology}

The Japanese small scale mushroom producers and retail outlet were interviewed to obtain information related to technological implementation and market 
chains of mushroom production in Japan. Other than that, information presented in this paper was collected through review of existing documents and interviews with small scale producers, retail shop, supermarket and government institute which are responsible for mushroom production and value chain in Sri Lanka. Much of the information was obtained from the Mushroom Division of Horticultural Crop Research and Development Institute in Gannoruwa, $\mathrm{Mu}$ shroom Development and Training Center in Ratmalana and Regional Agricultural Research and Development Centre in Makandura. These are the main service provider at the moment. They are also involved in offering training in mushroom production. The main objective is to development of technology for Oyster, Button, Straw and Milky mushroom and promote it as a women's enterprise. Some major supermarkets provided information on cultivated species being sold, their retail prices and countries of production. In this study, every main steps of production process shown in Figure 1 have been discussed in details with the differences of cultivation process between Japan and Sri Lanka in terms of technological implementation in the industry.

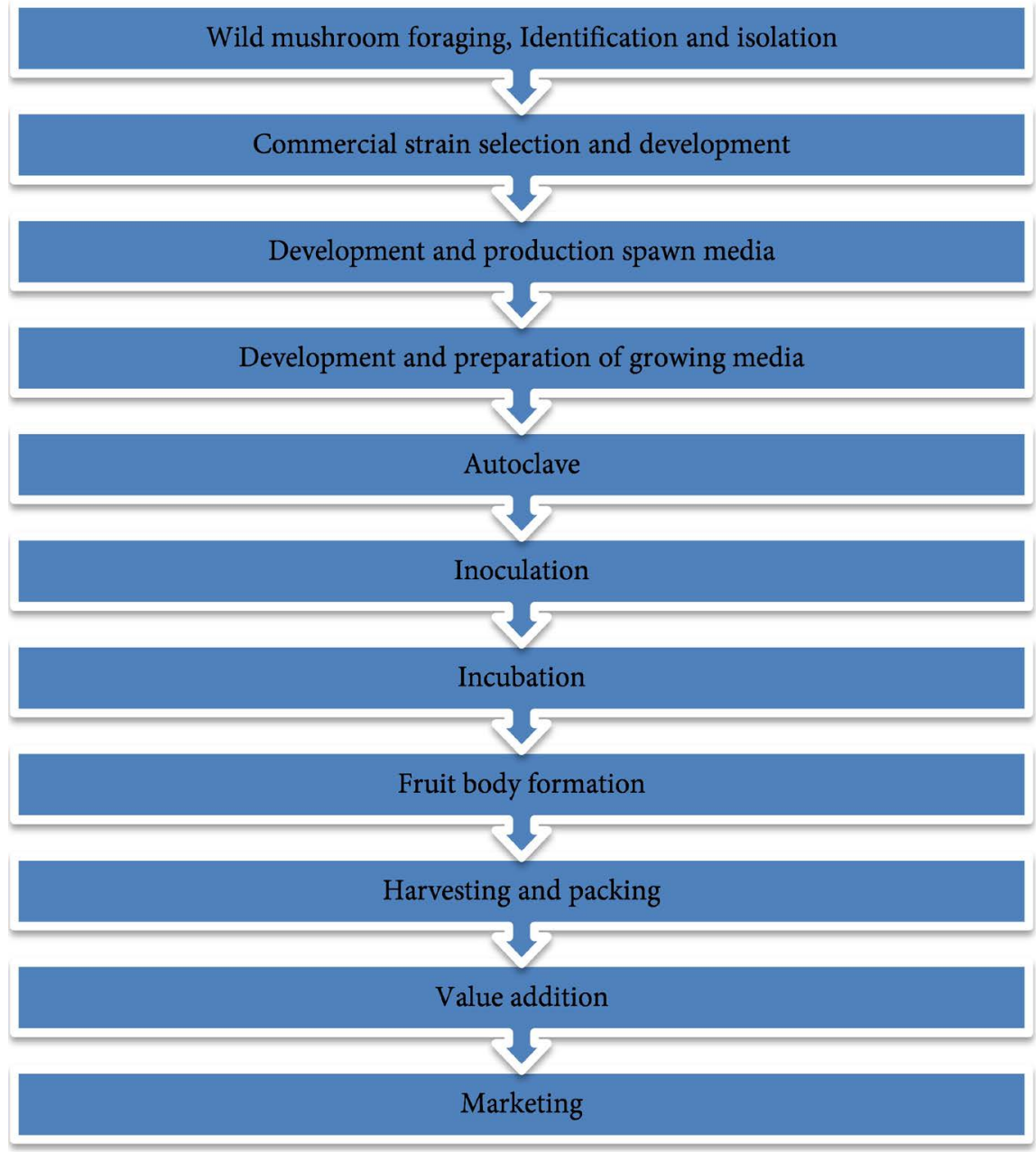

Figure 1. Main steps of isolation, identification and production process of mushrooms. 


\section{Wild Mushroom Foraging, Identification and Isolation}

Most wild edible mushrooms in Sri Lanka are mainly located in wet and intermediate zone. They include Volvariella volvacea, Termitomyces eurrhizus and Schizophyllum commune species (Figures 2(a)-(c)). Though wild edible mushrooms are popular among Sri Lankan, compared to other competitive food items, consumer behavior towards buying cultivated mushroom is rare. This could be attributed to limited availability and lack of awareness on the economic, nutritional and medicinal benefits of cultivated mushrooms.

Mushroom foraging is done by individual people. There is no any kind of community gathering for mushroom hunting in Sri Lanka. In every year, few cases of mushroom poisoning have been reported [16]. Other hand, some medicinal species in Sri Lanka, especially Phallus sp. (Figure 2(d)) have been rejected by people because of misleading information on particular mushroom as poisoning species. It is known in China as the flower of fungi and its medicinal properties are extremely valuable. Phallus $s p$. is a prized edible mushroom said to stimulate circulation and have antitumor properties [17]. Six Dictyophora species and three Phallus species (Dictyophora indusiata and Hymenophallus indusiatus are synonyms of Phallus indusiatus) are included in the checklist of edible fungi in China [18].

Wild mushroom foraging is still popular in Japan even though most of well-liked mushrooms types are commercially available in super market throughout the country. Japanese gather as community members (Figure 3) and looking for mushrooms with experienced and knowledgeable guide. As a result, mushroom poisoning has been reduced. The isolation of valuable wild strains is important. Harvested wild mushrooms are screened by experts, and then quickly and efficiently cultivated on prepared media. The institutes conduct enormous amounts of tests on cultivation to find new and better strains of mushroom. Most of beneficial mushrooms species in Japan which have food and medicinal values have been isolated and growing in special agar or liquid media for spawn production. Enormous experiments have been conducted on every single species to identify their properties and increase the production efficiency. Some forest clusters are inoculated by liquid or solid inoculums of suitable and valuable wild strains and allow them to grow naturally. Those programs also increase considerable amount of wild mushroom production.

Wild mushrooms in Sri Lanka, most of them have not yet been isolated nor properly store for further usage. Studies have to be done for identification, isolation and development of valuable wild strains. Among Sri Lankan, there is a potential demand towards Termitomyces species because of texture and taste of the particular wild mushroom. Neither commercial spawn production nor commercial mushroom cultivation of Termitomyces species can be seen in Sri Lanka.

\section{Commercial Strain Selection and Development}

After isolation of strains, several studies have to be done for improvement of 


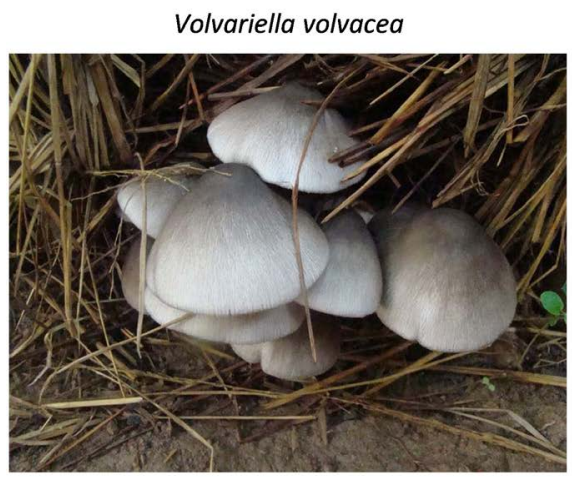

(a)

Schizophyllum commune

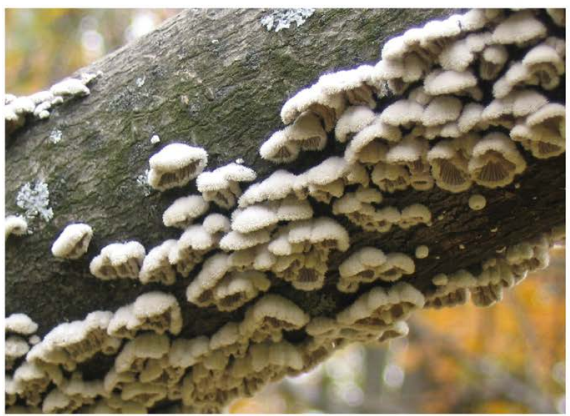

(c)

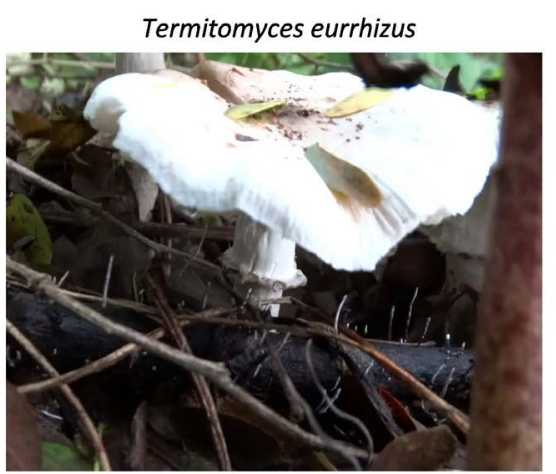

(b)

Phallus indusiatus

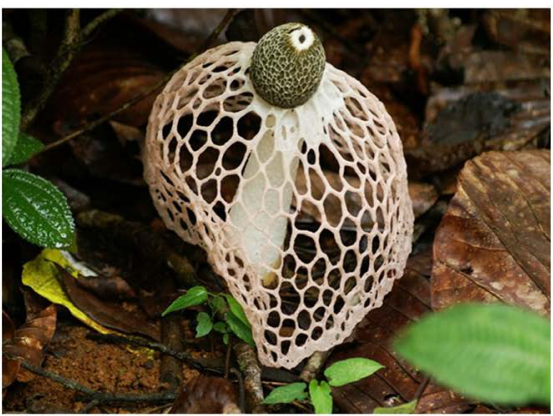

(d)

Figure 2. Few wild mushroom strains in Sri Lanka.
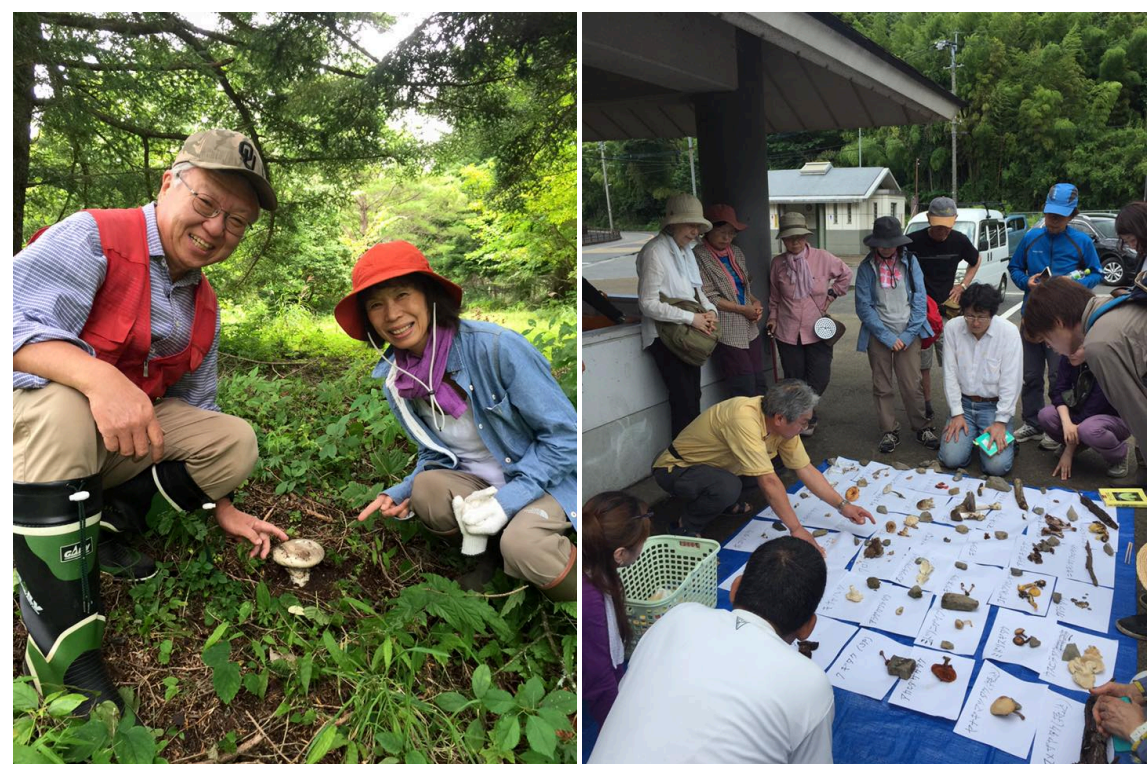

Figure 3. Wild mushroom hunting and identification as a community.

strains. Revealing of suitable strains for local environment is vital process when there is no controlled environment. Hybridization can be done and select quality and effective new mycelial strains for further commercial mushroom production. 
The Oyster mushroom, paddy straw (Volvariella volvacea) and milky (Calocybe indica) mushrooms are some of the high potential cultivable mushrooms in Sri Lanka since they can be grown well under tropical and subtropical condition [2]. P. ostreatus, commonly known as American oyster, is grown worldwide, and China is the major producer. It is popular in Sri Lanka as a vegetable and as an ingredient in soup due to its high nutritive content, unique flavor, and medicinal properties. Oyster mushroom cultivation has increased tremendously throughout the world during the last few decades. However, we found that almost all the cultivators are growing $P$. ostreatus for commercial purposes. This species is most preferred among the available species because it is very easy to grow under the low tech mushroom farming being practiced in Sri Lanka. The Oyster mushroom and Straw mushroom are cultivated at the research station of Export Development Board (EDB), Ratmalana, Sri Lanka to develop growth conditions and improve yields of mushrooms for local consumption and export [19]. Volvariella or Chinese mushroom [2] requires a high temperature $\left(35^{\circ} \mathrm{C} \pm 2^{\circ} \mathrm{C}\right)$ for better and early hyphal growth. Also $32^{\circ} \mathrm{C} \pm 2^{\circ} \mathrm{C}$ and $80 \%-90 \% \mathrm{RH}$ (relative humidity) are needed for the formation of fruiting bodies and it is a popular variety among people because of its distinct flavor, pleasant tastes, higher protein content and shorter cropping duration compared to other cultivated mushrooms [3]. However, growth characteristic is shown that particular species suits for outdoor cultivation in intermediate zone of the country where paddy straw abundantly available. Despite having the largest commercial demand, we found that button mushrooms are not being commercially cultivated in Sri Lanka. The main reason given was that these mushrooms require more advanced cultivation techniques which most growers in Sri Lanka cannot afford. Some major supermarkets are selling button mushrooms imported from the China. This ensures a readily available market for anybody wishing to venture into commercial button mushroom production in the country.

In Sri Lanka, mushroom cultivation is highly rewarding because of the prevailing climatic conditions. The technology profitably has to be taken because of land and agricultural residues have become limiting factors for cultivation of any sort of mushroom. However, Selection of strains for commercial cultivation purpose has to be made in order to market price, abundance of substrate, cultivation condition and requirements, susceptibility for pest and disease, self life and crop cycle of the strain.

Most of commercial species in Japan, there are few variety which differ in terms of color, texture, production efficiently, self life and active compound in side fruit body. They have developed their wild mushroom strains towards commercial cultivation purpose. Generally, genetically modification of mushroom strains is not practiced instead of using cross breeding and conventional biotechnology process. Even though it is not practiced, they have acquired technology for production and development of novel hybrid strains by somatic cell (protoplast) fusion, optimization of PFGE separation of fungal chromosomes, 
introduction of genetic markers into strains via introgression breeding and development of transformants and transgenic strains through Agrobacterium system or particle bombardment [20]. The availability of mushroom strains with genuine novel characters and improved productivity confirms the industry with new options for solving the problems, increasing the bio-efficiency percentage and usage. Up to the mid 1980s, growers were obliged to cultivate $F$. velutipes mushrooms under dark conditions to prevent the discoloration of the caps and stems towards brown color due to light exposure. Hokuto M-50, a cultivar that does not darken on exposure to light was developed in 1985. It has been developed H. marmoreus (buna-P), a mutant induced by UV and it produces a large quantity of the mushrooms [15].

\section{Spawn Media Development and Spawn Production}

There are several government institutions and private agribusiness companies producing spawn currently. Paddy seed is mostly used as substrate for spawn. Pathmashini et al. have evaluated kurakkan, maize, sorghum and paddy grain media for spawn production and find out the most suitable media for $P$. ostreatus spawn production. Kurakkan spawn has showed a faster rate of mycelium growth during the spawn run. Paddy spawn has showed a markedly slow rate of mycelium growth compared to all other spawn types. Polypropylene bags (200 gauges, $37.5 \mathrm{~cm}$ long and $17.5 \mathrm{~cm}$ wide) have been used as container [13]. Used glass bottles of alcoholic beverages are mainly used as containers for spawn (Figure 4). While most glass bottles of soft and full size alcoholic drinks are returned for reuse, quarter and half size bottles of arrack are not returnable. That makes them available in abundance for use in spawn production. Customers for spawn are small scale individual growers and community groups. There are also some nongovernmental organizations which buy spawn for promotion of mushroom production among their beneficiaries.

The medium scale and some small scale producers in Japan maintain their own spawn stock after purchasing a strain form outside institute or strain developers. There are spawn center where farmers can buy solid spawn as well as liquid spawn. About $60 \%$ of $F$. velutipes production has done with liquid inoculation in Japan. Since 2008, the spawn-center has produced liquid spawn for growers of Enokitake and King oyster. Now the spawn center supplies 7000 tanks of liquid spawn a year for 5 incubation-centers affiliated with JA-Nakano-city. The supply of liquid spawn is equivalent to 140 million culture bottles for Enokitake growers [15].

\section{Growing Media Development and Preparation}

The perfect substrate combination is one of major factor for a successful mushroom cultivation other than reliable spawns and suitable environment conditions. Substrate preparation is known as the heart of the process thus a substrate that can provide adequate nutrients for the mycelial growth and fruiting body 


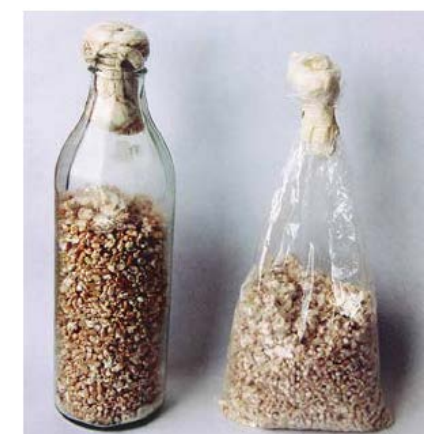

Figure 4. Two types of solid spawn containers.

formation which play key role in determining the success of the cultivation [3]. Now Pleurotus species is the predominately cultivated species in Sri Lanka [21]. Unlike other mushrooms, Pleurotus species has unique adaptation to a wide range of lingo-cellulosic substrates like straw, sawdust, rice hull, etc. It has been reported that $P$. ostreatus gave maximum biological efficiency on sawdust. Softwood sawdust like mango and cashew are known to be more suitable than hardwood sawdust [13]. Presently in Sri Lanka sawdust is commonly used and is the preferred medium at commercial scale. It is amended with rice bran and a protein supplement as the growth substrate for the cultivation of Oyster mushrooms. Soya and green gram powder are frequently included protein supplements in substrate preparation. However the cost of production can be minimized with the substitution of cheaper nitrogen sources such as animal manure which can supply a substantial amount of major plant nutrients, secondary nutrients [22]. Normally in Sri Lanka, Department of Agriculture (DOA) recommendations are followed for preparation of media in the ratio of saw dust $(40 \mathrm{~kg})$, soft rice bran $(4 \mathrm{~kg}), \mathrm{CaCO}_{3}(800 \mathrm{~g})$, and $\mathrm{MgSO}_{4}(80 \mathrm{~g})$. Those are thoroughly mixed with water. The correct water content is checked by pressing the medium by hand. The amount of water has to be added is decided by previous experiences as practical method. The mixed medium is filled into polypropylene bags [3] [13]. In 2017, DOA has introduced new machineries for media mixing and filling. After feeding of substrates and water to the machine with their ratio, media are mixed mechanically. The mixed media is filled in to polypropylene bag with automatic filling mechanism. Because of lack of promotions, particular machineries are still not popularized among mushroom farmers in Sri Lanka.

The yield of straw mushroom depends on the cultivation methods and compost medium. Rice straw was practically the only material used for preparing the growing medium for $V$. volvacea. It is the material freely available in Sri Lanka and therefore, this cultivation is ideal in rural area where paddy straw is abundant after each paddy harvest. Paddy straw composting has been done by soaking dried paddy straw $(50 \mathrm{~kg})$ in a $2 \%$ lime solution for four hours and excess water was allowed to drain. Paddy straw has been spread on a clean cement flow as a thin layer. Urea (1\%), gypsum (5\%), measured on dry weight of paddy straw have been evenly spread on the wetted straw and mixed well to prepare compost 
medium. Straw alone is not sufficient as a composting material as it contains a little quantity nutrients and has a slow rate of decomposition. Therefore, straw mushrooms presently are grown in some other materials such as cotton waste, sugar cane bagasse, dried banana leaves, oil farm bunch waste etc. [2]. It has been reported that chopped maize stover used as substrate for mushroom production. The maize stover is cut into pieces of about $3 \mathrm{~cm}$. The same process which was used for paddy straw also practiced on maize stover. Otherwise, the chopped substrate in dipped in powdered soap, and washed in a fashion similar to hand washing clothes. Then it is left to stand for five to ten minutes in the container. The substrate is then rinsed in clean water until almost all the soap bubbles have disappeared from the rinsing water. After this the substrate is packed in clean sacks or left in perforated containers overnight to drain. The moisture content is checked by squeeze test before packing in plastic growing bags. Both Polypropylene bag and bottles are used for filling growing media. The outdoor cultivation method which was introduced by the Department of Agriculture few years ago had some issues and farmers are reluctant to produce mushrooms due to difficulties to control environment factors such as temperature, $\mathrm{RH}$ and pest problems. It has been reported effective alternative indoor cultivation method under controlled environment for cultivate straw mushroom which is highly sensitive to the climatic conditions and their fluctuation [2] [3]. The method for production of artificial log had been introduced by one of research institute in Sri Lanka. It has been described that growing medium (sawdust, compost or straw) mixed with binding agent (cement or plaster of Paris) to prepare logs by using mold. Cost effectiveness and feasibility cannot be confirmed because of lacking of information.

In Japan most of these processes were done by mechanically with pre set ratio of substrates and water. According to the type of mushroom strains, the container is selected. Usage of reusable bottle is cost effective and it is cut off expenses for polypropylene bags. As shown in Figure 5 mechanical processes are easy to implement. Handling and storing are simple in order to the design of bottle and tray. Space requirement is very low compare to bag cultivation.

Bag culture of shiitake has increased rapidly in conjunction with a decrease in log cultivation because of its convenient handling, compared to the difficulty in handling heavy logs, and the more effective use of indoor space. Deciduous oak sawdust substrate is supplemented with rice bran, wheat bran or corn bran and contained in micro-filtered polypropylene bags. The substrate for Enokitake production was traditionally based on the sawdust of Japanese cedar. At present, most growers use ground corncobs as substrate. Commercial production of most Bunashimeji is on a substrate of sawdust or corncobs contained in bottles of 850 $\mathrm{ml}$ in volume with the opening of $58 \mathrm{~mm}$ in diameter The cultivation of Nameko (Pholiota nameko) and Hiratake (Pleurotus ostreatus) was also based on log cultivation in 1950 but it changed over to bottle cultivation in 1960 [15].

Mushroom production has become more popular in Japan, along with a move 


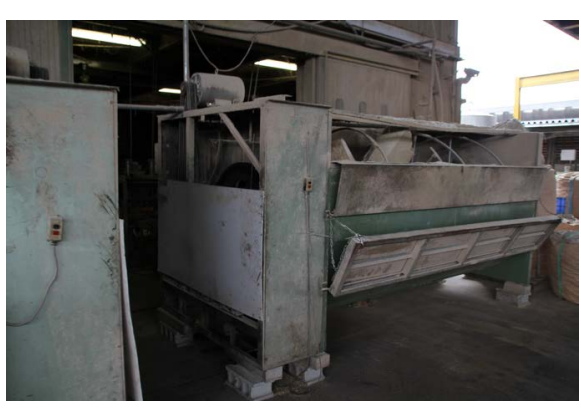

(a)

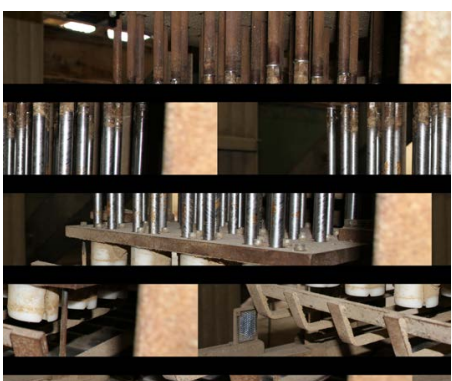

(c)

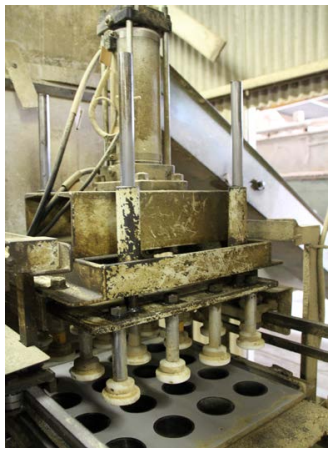

(b)

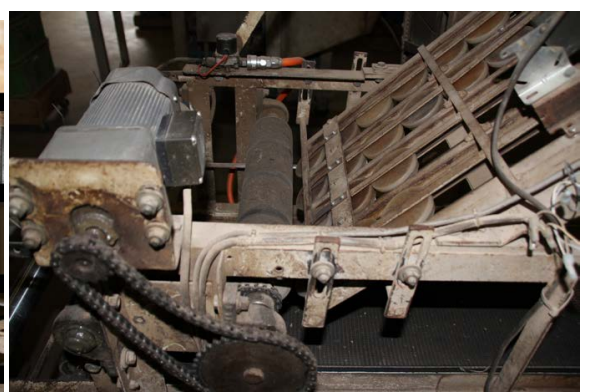

(d)

Figure 5. (a) Substrate preparation; (b) Filling; (c) Spawn holes making; (d) Placing a cap of bottle by using automated machines.

to polypropylene bottles. The production of Bunashimeji (Hypsizygus marmoreus) began using sawdust substrate in bottles while production of Maitake (Grifola frondosa) was done by using bags cultivation method with sawdust substrate in 1970. Currently $26 \%$ of production is in bottles. King oyster (Pleurotus eryngii) production by using bottle cultivation was introduced in 1993. At present, most production of Enokitake, Bunashimeji, King oyster, Nameko and Hiratake are on sawdust or corncob substrates contained in bottles. In general Maitake growers and the big production companies use broadleaf sawdust substrate $(2.5,1.0$ or $1.5 \mathrm{~kg})$ contained in micro-filtered plastic bags. In 2001, a company began the production of Maitake in bottles. This was the beginning of so called "Mushroom War" in Japan. Large Maitake production companies based on bag culture use automatic equipment for bag forming, heat-attachment of micro-filter, filling of the substrate before autoclaving as well as inoculation after cooling [15].

\section{Autoclave or Disinfection of Media}

Autoclave is the physical process of destroying the bacteria or microorganisms in the media. It allows to growth of required mycelia without any competition with other microbes for nutrient. Normally saw dust media prepared for indoor cultivation is exposed to autoclave process which considered as most effective sterilization method and destroy most of bacteria, bacterial spore and pathogen in the media. In Sri Lanka most of mushroom producers have used to use big 
barrel with water which is heated by fire wood to produce steam. Some of them uses same barrel (Figure 6(a)) by putting a wood holder in the bottom to avoid sinking media bag in the water. Tight cover lid makes accumulation of generated steam inside the barrel to increase pressure. In order to pressure temperature also increased. Others use one barrel for steam generation and few separate barrels have been connected through metal pipes (Figure 6(b)). Those barrels provide space for holding substrate. Major problem in this method is temperature of the chamber cannot reach recommended level about $121^{\circ} \mathrm{C}$. In case some pathogenic spore can be survived and contaminate media while incubation. As a remedy the time duration of steaming can be expanded. Meanwhile it increases fuel cost and total time duration of the process.

Sterilization with chemical solutions is the other process of destroying microbes. This method is not practiced for saw dust media but widely used for sterilize paddy straw and maize stover media. It has been reported that growing media for $V$. volvacea has been prepared using paddy straw and cotton waste. Paddy straw composting has done by soaking dried paddy straw in a $2 \%$ lime solution for four hours. It is not a complete sterilization because pathogenic spore can be remained in the media.

Japanese mushroom producers generally use boiler for steam generation and considered as an efficient method for autoclave. For commercial production, barrel autoclave is less effective compared to electrical and furnace oil or diesel boilers (Figure 7) which able to produce steam in the state of high pressure and high temperature. Presently, farmers tend to use electric boiler instead of furnace oil boiler because of low maintain cost and cheap electrical power.

\section{Inoculation}

The grain or liquid spawns are introduced or inoculated into the sterilized compost media. Grain spawn is broken loose by shaking the bottle violently or using a disinfected wire for easy spreading on the substrate. The spawn is spread on the top surface of the substrate. Higher spawning rates than normal can also be used to have quicker substrate colonization and fruiting. Average house hold producer, inoculation process is conducted at open environment surrounded by few burning flames. It reduces contamination some extent but still has high risk of contamination.

In Japan most of producer including small scale producers, pathogen free clean isolated environment is used for inoculations. Autoclaved bottles are kept temporally nearby inoculation chamber until cooling down. Particular area is also treated by filtered air using heap filter unit. Air pressure of inoculation room and temporary store room is bit higher than outside environment, so airborne pathogen and spores cannot be entered to the rooms. Moreover, there are few UV light which are operated while the room is not occupied (Figure 8). Successful rate without contaminations has been reached nearly $100 \%$ due to sanitation precautions. According to the requirements, spawn has been produced 


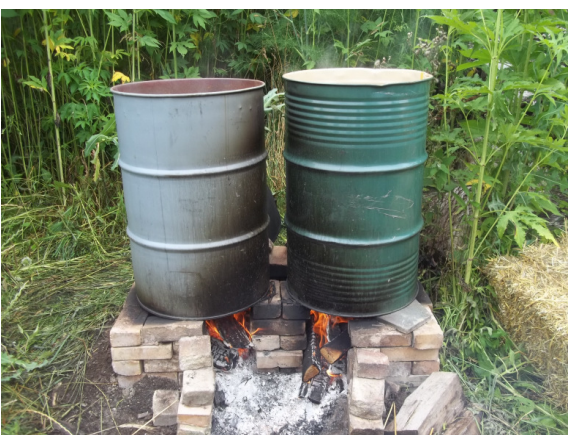

(a)

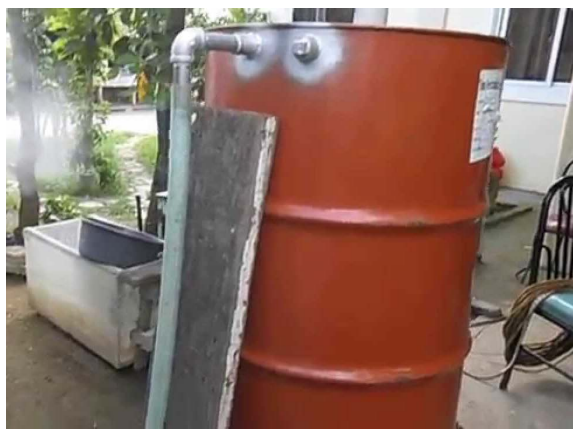

(b)

Figure 6. Conventional autoclave process by using barrels; (a) Steam generation and media storing in same barrel; (b) Separate barrels used for steam generation.

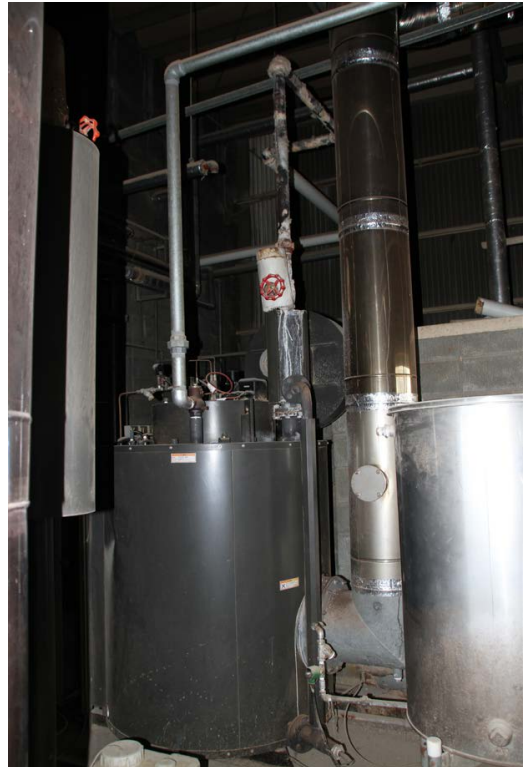

Figure 7. Technically advance boiler used for steam generation.

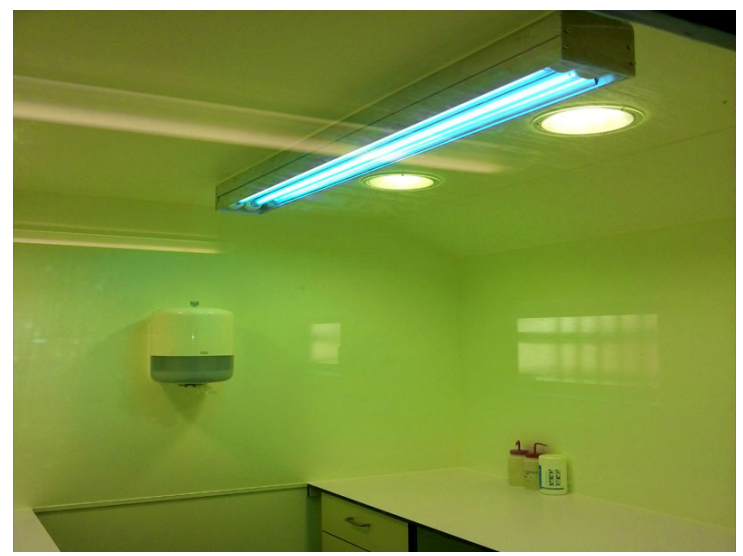

Figure 8. Inoculation chamber with UV light.

by them self and machineries are used to operate inoculation process. Solid spawn is produced by using grains and bio reactor is used for produce liquid in- 
oculums purposively.

\section{Incubation}

The inoculated compost bags or bottles were kept in the darkness until the mycelia has completely penetrated to the bottom of the substrate [3]. The bags are incubated for five to six weeks before being moved to the fruiting room. Time duration and temperature of the incubation depend on the cultivated species. In Sri Lanka, mushroom producers don't use well insulated incubation room. Exclusive of providing shade for mycelia growth, major environmental conditions cannot be controlled.

The mushroom houses are constructed in such a way that they provide the general conditions specially temperature range and $\mathrm{RH}$. There is a wide variability in terms mushroom growing houses. Even small scale producers in Japan, well insulated incubation chambers are used (Figure 9). Special insulating material is attached to walls of the chamber to avoid heat transfer through wall. Ventilation is a vital process while growing and colonizing of mycelia. So, ventilators are operated throughout the incubation period. There are some farmers who have incubation facility other than media preparation and inoculation. They obtain inoculated bottle from incubation centers. Bottles of colonized substrate are distributed to growers 10 days after inoculation in incubation centers. Growers do not need autoclaves, machines for mixing, filling and inoculation of substrate. They can devote their time to pinning, growing and harvesting [15].

\section{Fruit Body Formation}

In the fruiting room the substrate bottles or bags are opened and sometimes few holes are punched on the sides of bags. These holes allow gas exchange and are also places from which mushrooms can erupt from in addition to the main opening of the bags. Generally, the spawn running phase requires high temperature, low humidity, high carbon dioxide concentration and low light intensity. The fruiting phase requires lower temperatures, more light, more oxygen and high humidity. Frequent light mist irrigation is provided to maintain a favorable humid atmosphere for the mushroom development [3]. Fruiting begins one to two weeks after moving the fully colonized growing bags into the fruiting room. The fruit bodies will keep coming from the bags, in flushes, for about three months.

The biological efficiency of Enokitake is now $95 \%$ - 130\% due to improvements in cultivation technology compared with $60 \%$ to $75 \%$ BE in the early-1980s. In order to induce preferable fruiting, growers implement a unique Kinkaki which removes only the peripheral portion of the original inoculum leaving the center of the inoculum as dome-shape. Average yields in general for Bunashimeji growers are 180 to $200 \mathrm{~g}$ per $850 \mathrm{ml}$ bottle with a biological efficiency of 95\% $105 \%$ [15]. It has been mentioned blue light affect on high yield of fruit body. So, fruit body chamber has been lighted with blue light LED (Figure 10(b)). It 


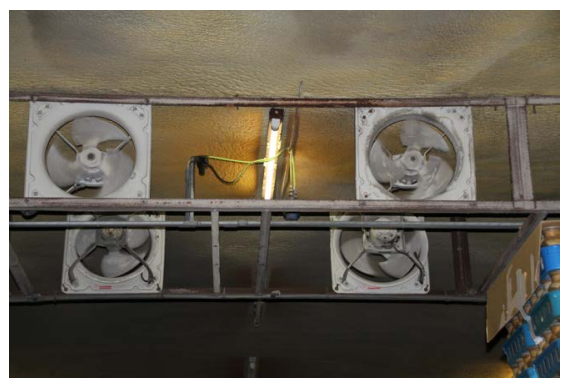

(a)

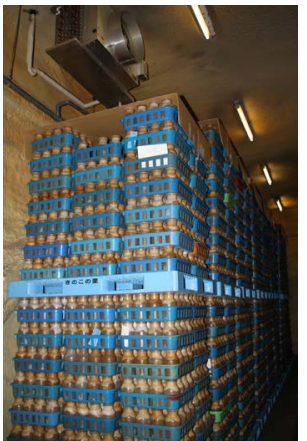

(b)

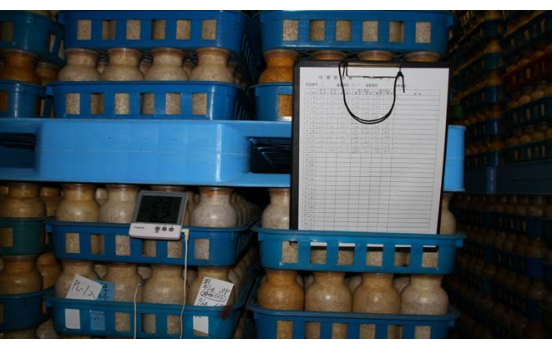

(c)

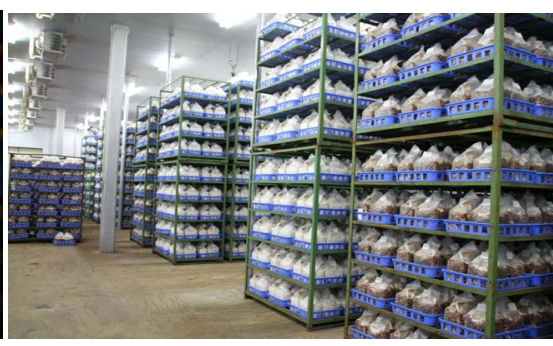

(d)

Figure 9. Incubation chamber.

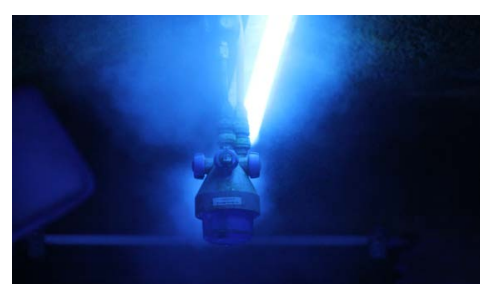

(a)

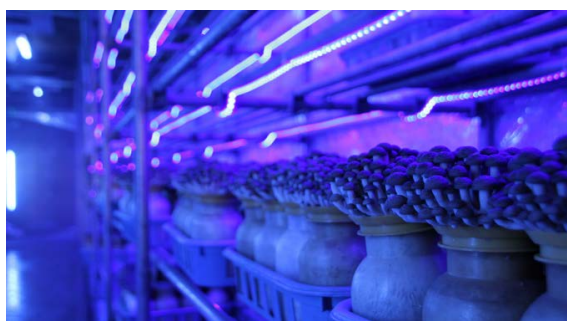

(b)

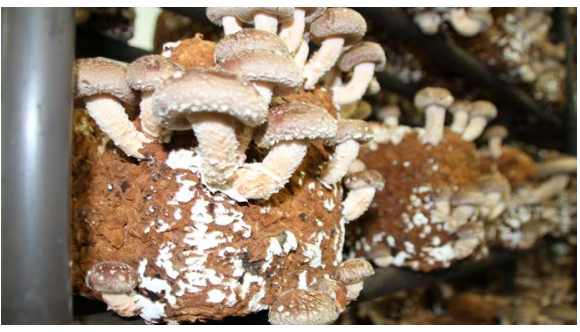

(c)

Figure 10. Fruiting body chamber (a) Humidifier units; (b) Blue color LED; (c) The bag has been removed for fruit body formation of Shiithake wood chip cultivation.

increases fruit body formation and reduces energy consumption compared to conventional bulbs. Automated RH controlling system is used. RH sensor detects the humidity in the chamber and operates the mist blower (Figure 10(a)).

Pests and diseases are major constraints to the mushroom cultivation in Sri Lanka. Oyster mushroom was caused by $T$. harzianum. The green mould accounts for over 20\% yield loss in Oyster mushroom cultivation in Sri Lanka [19]. Deformations of mushroom heads have frequently been reported. It has continued to occur in Sri Lanka as there were no measures taken to control the disease 
[23]. Preventing actions for excising diseases are vital for mushroom industry. Moreover, precaution action and keeping sanitation are also very important.

\section{Harvesting and Packing}

The machines have been placed to minimized handling damages at the process of harvesting, weighing and packing (Figure 11). Physiological disorders are the main causes of postharvest loss of mushroom and limit the availability of fresh mushrooms to Sri Lankan consumers. Physiological disorders such as shriveling, liquefaction, and textural and flavor changes shorten the shelf life [24]. Storage temperature further enhances the physiological disorders as the rate of biological reactions increase with increase in temperature [25]. Storage of mushroom at $0^{\circ} \mathrm{C}$ and $95 \% \mathrm{RH}$ has been reported to be the optimum condition to extend marketable life. It may not be practical to store fresh mushrooms at $0^{\circ} \mathrm{C}$ as temperatures inside refrigerators and display cabinets, which could be used for low temperature storage of perishable products, are maintained between $6^{\circ} \mathrm{C}$ and $10^{\circ} \mathrm{C}$. The shelf life of these packages is about 4 days under the low temperature conditions used in supermarkets.

The condensation of moisture inside these packages, off odor development, and off color development are common problems in mushroom packaging, probably due to low permeability of packaging films to water vapor, oxygen, and carbon dioxide. Moisture condensation is further aggravated under low RH conditions of refrigerated storage. Modified atmosphere packaging is reported to be the most economical and effective method of extending the shelf life of mushroom [25]. In here, a low $\mathrm{O}_{2}$ and high $\mathrm{CO}_{2}$ environment resulting from respiration has been successful in slowing down deterioration and growth of microorganisms in fresh mushrooms. The success of modified atmosphere packaging is due to the creation and maintenance of an optimal in package atmosphere that is determined by the respiration rate of the product and the permeability of the packaging film to oxygen and carbon dioxide. Lasanthi et al. have reported a suitable packaging material for storage of Oyster mushroom at $8^{\circ} \mathrm{C}$ and $70 \%$ relative humidity and to identify a suitable washing treatment to maintain mushroom quality. The effectiveness of magnesium oxide as a carbon dioxide scavenger in extending the postharvest life has also tested [24].

In Japan, normally mushrooms are packed in small container or air accumulated pack to reduce damage while handling and transporting (Figure 12). Any washing treatment for increment of self life is not practiced because washed mushroom has been rejected by Japanese customers. Enokitake is traditionally packaged and marketed in a $100 \mathrm{~g}$ pack but now an entire bunch of Enokitake can be vacuum packaged and shipped. Hiratake production has steadily decreased since 1989. In 2009 it was down to $7 \%$ of its maximum production in the past. The Japanese considered Hiratake to be one of the best tasting mushrooms for a long time. The cause of the decrease of this fungus may be that dealers and buyers are reluctant to sell Hiratake because of inherent disadvantages, such as the short postharvest shelf life [15]. 


\section{Value Addition}

The value addition of mushroom is not popular among small scale producers in Sri Lanka because their production capacity is very low and fresh mushroom demand in the market has acquired their total production. Still mushroom producers in Sri Lanka have opportunities to go for higher production and value addition to their product. It allows supply to the demand throughout year while putting surplus price to value added products. In other hand, value adding reduces post harvest loses due to short self-life of fresh mushroom. Because of lack of production and value added products, foreign products have been penetrated to the market place (Figure 13). Presently, Sri Lanka imports canned paddy straw mushrooms and button mushrooms from China and this mushroom is available in most of the supermarkets.

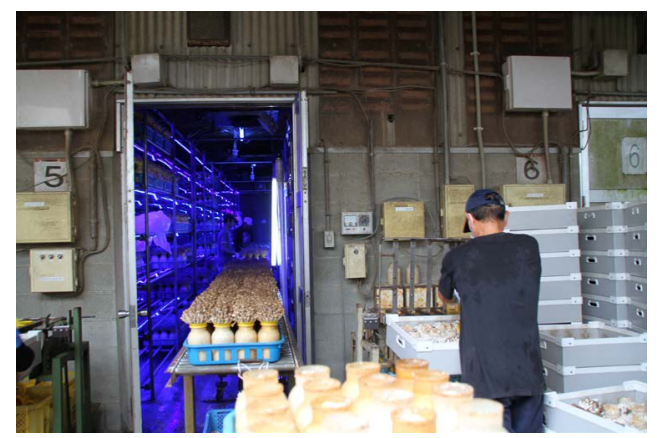

(a)

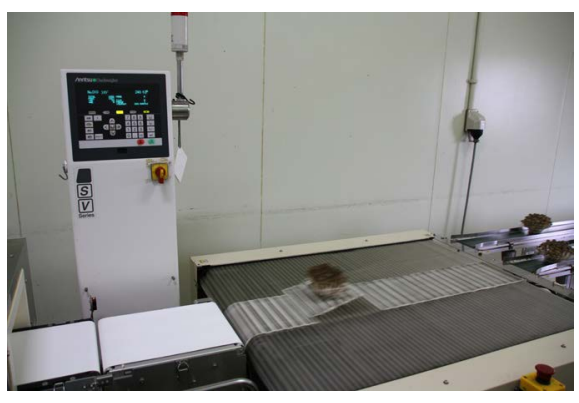

(b)

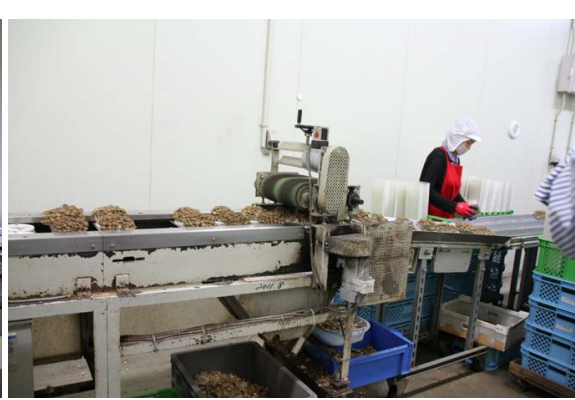

(c)

Figure 11. (a) Harvesting by using machine; (b) Weighing; (c) Packing.

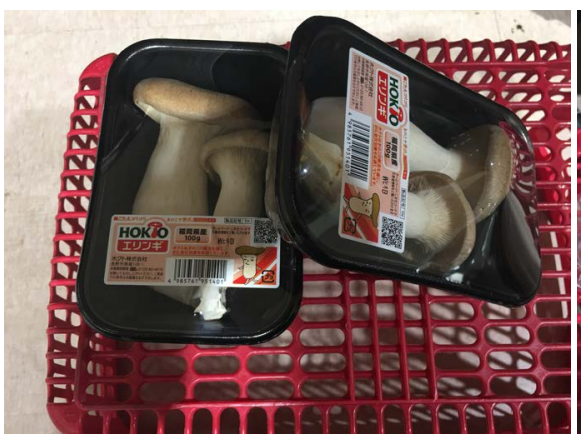

(a)

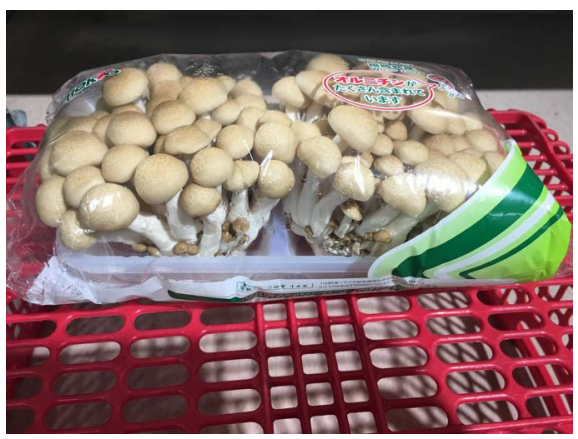

(b)

Figure 12. (a) Small plastic container; (b) Air accumulated pack. 


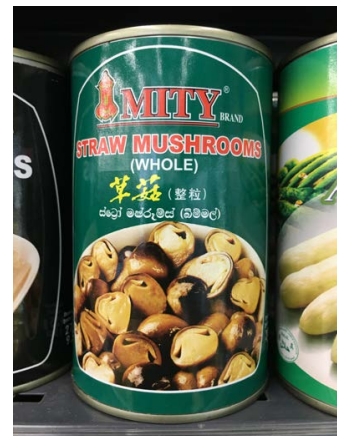

(a)

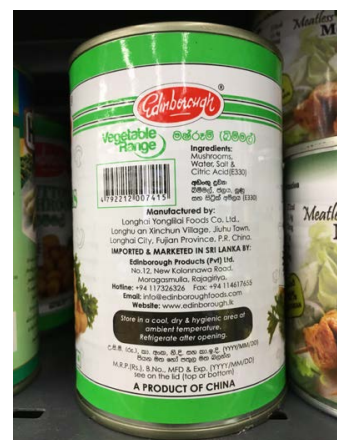

(c)

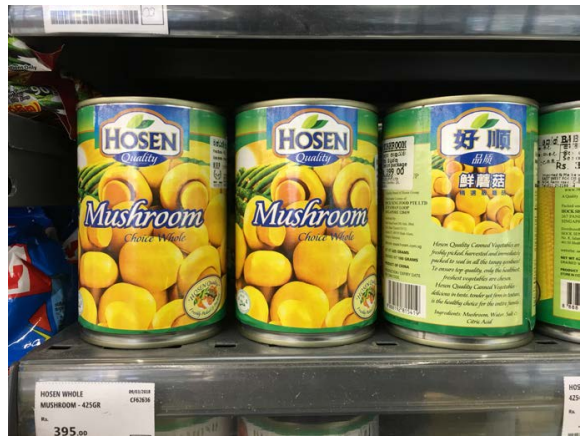

(b)

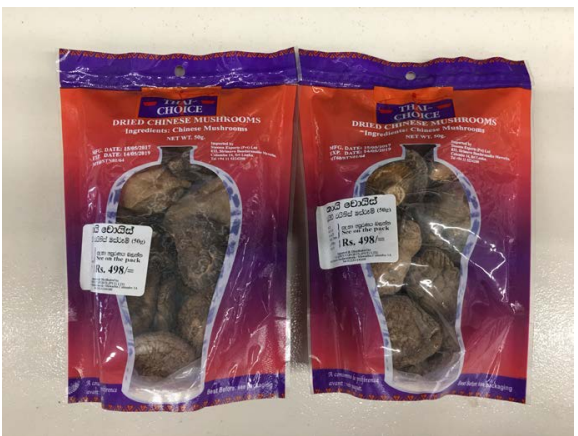

(d)

Figure 13. Imported mushroom products (a) Canned $V$. volvacea mushroom; (b) Canned A. bisporus mushroom; (c) A product of China; (d) $L$. edodes mushroom imported from Thailand.

\section{Marketing}

The mushroom producers in Sri Lanka have to be developed in order to 4 Ps of marketing mix. Product: Oyster mushroom which is being commercially cultivated by almost all the mushroom farmers but button and Oyster mushrooms are available in some major supermarkets imported from foreign country. So, farmers have to be encouraged to cultivate valuable and divers mushroom types. Value added product ranges have to be developed to gain surplus production. To maintain the quality of product, new technique, utensils, packing method should be introduced. Harvest can be categorized according to color and shape, in order to that high quality product range can be maintained. Price: To capture higher market share, prices can be set concerning the product level and buying behavior of the customers. High quality and value added product range can be introduced with demanding a premium price. Place: Mushroom can be marketed locally through a free market chain. Value added premium products should be introduced export market. Promotion: The introduction of the nutritional value and health benefit of mushroom can be increased the wiliness towards consumption of mushroom product among Sri Lankan.

Most of the cultivated mushrooms in Sri Lanka are used in restaurants especially, major hotels and lodges. Individuals living in proximity to mushroom cultivators also provide a market for the crop. All the major institutions involved in mushroom cultivation indicated that the current production does not meet 
the demand for mushrooms in the country. This is evidenced by the importation of most of the mushrooms being traded in the country's supermarkets. The selling prices of Oyster mushrooms, by cultivators, depend on where they are being sold. The prices range was from LKR 240 (1.47) to LKR 430 (USD 2.63) per kg in 2017. Most of the major supermarkets sell Button and Oyster mushrooms.

We think that one of the ways to popularize mushroom cultivation in the country is to bring some of the most preferred wild edible species into artificial cultivation. The majority of people are already familiar with wild mushrooms and it would be much easier to accept them than foreign cultivated species. There are fears that continued loss of forests will lead to reduced yield and probably complete loss of some of the wild edible mushrooms. Success in cultivating these species will ensure their continued availability. This will also make them available in fresh state throughout the year rather than seasonal as is the case now. There have been some efforts in the past to bring these wild species into cultivation. However, up to now no one has managed to find a way to produce the fruit bodies of any of the indigenous edible mushrooms recorded in the country. There is need for continued research efforts aimed at finding ways to bring some of the popular wild edible mushrooms into cultivation. With advancements in biotechnology and increased knowledge in mushroom cultivation, we should be able to cultivate some of these mushrooms.

There are no well defined markets and market channels for mushrooms currently. This has led to wide variations in prices cultivators sell their mushrooms. Some sell directly to consumers at very low prices because they do not have access to major supermarkets and hotels where they can fetch more for their produce. Organizing mushroom growers into associations would be one major way of dealing with this challenge. Despite the economic, nutritional and medicinal benefits that mushrooms can offer, the governments as well as nongovernmental organizations in the country are giving very limited attention to mushroom production. This hinders development of the industry in the country. Government support cannot be ruled out if promotion of mushroom production is to be successful.

There are a number of factors that affect or have potential to affect mushroom cultivation in Sri Lanka. The current method used for chopping rice straw and maize stover is very tedious and inefficient. This is done by placing maize stover on a piece of wood or small log and use a knife to chop it into pieces of about $3 \mathrm{~cm}$ long. This is an area where engineers in the country could do something about. This would be by way of developing a simple, low cost tool that will ease this process and improve efficiency. Lack of technology, production know-how and awareness on economic, nutritional and medicinal benefits of cultivated mushrooms is also a limiting factor to the development of mushroom production in the country. Unlike the growing of most field crops, mushroom cultivation requires some special knowledge and skills. Training on cultivation techniques should be continued and there should be more awareness on the benefits of cultivated mushrooms. This would motivate people to cultivate as well as consume 
more mushrooms.

\section{Conclusion}

Currently $V$. volvacea and no more than two species of oysters are being cultivated, with success, in Sri Lanka. This shows that the country is still lagging behind in mushroom cultivation. There is a need to introduce and popularize other cultivated species of mushrooms. Sri Lanka has huge potential for mushroom farming because of the availability of large amounts of agricultural crop residues. There is also a high demand for mushrooms, locally as well as internationally. The country can take advantage of these factors to develop the mushroom industry. Continued research efforts to bring some of the native wild edible mushrooms to cultivation must be encouraged and supported. Wild edible fungi are well known by the majority of Sri Lankan and we think that they will be more willing to cultivate and consume mushrooms same or similar to what they are already familiar with. Commercial market pressures, health needs and basic interest in research have been important driving forces for the development and expansion in the established areas of fungal biotechnology. Cultivation practices to increase productivity, biochemical analysis of protein, fatty acid, polysaccharides, medicinal and immunological activities are very essential qualitative and quantitative parameters for good mushroom strains. So, basic research in this field has to be done. We are far behind to the new technology of production system using movable shelves to transfer the bottles, unmanned forklift trucks, automatic harvesting and packaging machines for the labor saving and lower costs are outstanding characteristics of the industry. However, in doing so the focus should be on developing low cost production technologies that can be easily adopted in the country. Mechanical engineers, biologist and mushroom producers should work together to accomplish the goal towards technical implementation of mushroom industry with low cost of production.

\section{Conflicts of Interest}

The authors declare no conflicts of interest regarding the publication of this paper.

\section{References}

[1] Islam, S. (2015) Cultivation Techniques of Edible Mushrooms: Agaricus bisporus, Pleurotus spp., Lentinula edodes and Volvariella volvocea. The Magic of Mushroom and Mould Biology, PHP-50306, Wageningen University, Wageningen, 33.

[2] Rajapakse, P. (2011) New Cultivation Technology for Paddy Straw Mushroom (Volvariella volvacea). Proceedings of the 7 th International Conference on $\mathrm{Mu}$ shroom Biology and Mushroom Products (ICMBMP7). https://www.researchgate.net/publication/268410626_New_cultivation_technology_ for_paddy_straw_mushroom_Volvariella_volvacea

[3] Rajapakse, J.C., Rubasingha, P. and Dissanayake, N.N. (2007) The Potential of Using Cost-Effective Compost Mixtures for Oyster Mushroom (Pleurotus spp) Culti- 
vation in Sri Lanka. Tropical Agricultural Research \& Extension, 10, 29-32. https://doi.org/10.4038/tare.v10i0.1868

[4] Bahl, N. (1998) Hand Book on Mushrooms. Oxford \& I.B.H. Publishing Co. Pvt. Ltd., 15-40.

[5] Andlauer, W. and Fürst, P. (2002) Nutraceuticals: A Piece of History, Present Status and Outlook. Food Research International, 35, 171-176. https://doi.org/10.1016/S0963-9969(01)00179-X

[6] Kruger, C.L. and MannSafety, S.W. (2003) Safety Evaluation of Functional Ingredients. Food and Chemical Toxicology, 41, 793-805.

https://doi.org/10.1016/S0278-6915(03)00018-8

[7] Hossain, S., Hashimoto, M., Choudhury, E.K., Alam, N., Hussain, S., Hasan, M., Choudhury, S.K. and Mahmud, I. (2003) Dietary Mushroom (Pleurotus ostreatus) Ameliorates Atherogenic Lipid in Hypercholesterolaemic Rats. Clinical and Experimental Pharmacology and Physiology, 30, 470-475. https://doi.org/10.1046/j.1440-1681.2003.03857.x

[8] Bobek, P. and Galbary, S. (2001) Effect of Pleuran ( $\beta$-Glucan from Pleurotus ostreatus) on the Antioxidant Status of the Organism and on Dimethylhydrazine-Induced Precancerous Lesions in Rat Colon. British Journal of Biomedical Science, 58, 164-168.

[9] Vasudewa, N.S., Abeytunga, D.T.U. and Ratnasooriya, W.D. (2007) Antinociceptive Activity of Pleurotus ostreatus, an Edible Mushroom, in Rats. Pharmaceutical Biology, 45, 533-540. https://doi.org/10.1080/13880200701498853

[10] Chioza, A. and Ohga, S. (2014) Cultivated Mushrooms in Malawi: A Look at the Present Situation. Advances in Microbiology, 4, 6-11. https://doi.org/10.4236/aim.2014.41002

[11] Fürst, P. and Kuhn, K.S. (2000) Fish Oil Emulsions: What Benefits Can They Bring? Clinical Nutrition, 19, 7-14. https://doi.org/10.1054/clnu.1999.0072

[12] Fang, Y.Z., Yang, S. and Wu, G. (2002) Free Radicals, Antioxidants, and Nutrition. Nutrition, 18, 872-879. https://doi.org/10.1016/S0899-9007(02)00916-4

[13] Pathmashini, L., Arulnandhy, V. and Wijeratnam, R.S.W. (2008) Cultivation of Oyster Mushroom (Pleurotus ostreatus) on Sawdust. Ceylon Journal of Science (Biological Sciences), 37, 177-182. https://cjsbs.sljol.info/article/10.4038/cjsbs.v37i2.505/galley/543/download/

[14] Ranathunge, P.R.M.P.D., Rankothge, C. and Wickremasinghe, S.L. (2010) Small and Medium Mushroom Enterp in Sri Lanka: A Case Study on the Innovation System involved, National Science Foundation (NSF), Sri Lanka. http://thakshana.nsf.ac.lk/slstic/NA-314/NA314.pdf

[15] Yamanaka, K. (2011) Mushroom Cultivation in Japan. World Society Mushroom Biology and Mushroom Products Bulletin, 4, 1-10. http://www.wsmbmp.org/source/WSMBMP\%20Bull\%204-1-10.pdf

[16] Fernando, R. (2002) The National Poisons Information Centre in Sri Lanka: The First Ten Years. Journal of Toxicology: Clinical Toxicology, 40, 551-555. https://doi.org/10.1081/CLT-120014644

[17] Lu, D. and Luo, C. (2010) A Study on the Biological Characteristic of Phallus impudicus. Journal of Xinyang Normal University Natural Science, 23, 242-244. http://en.cnki.com.cn/Article_en/CJFDTOTAL-XYSK201002022.htm

[18] Li, H., Mortimer, E.E., Karunarathna, S.C., Xu, J. and Hyde, K.D. (2014) New Species of Phallus from a Subtropical Forest in Xishuangbanna, China. Phytotaxa, 163, 
91-103.

[19] Wickremasinghe, R., Abeywickrama, K. and Abeythunga, D.T.U. (1998) Isolation and Identification of Fungi from Mushroom Composts and Evaluation of Their Biological Activity. Journal of the National Science Foundation of Sri Lanka, 27, 29-40. https://jnsfsl.sljol.info/articles/abstract/10.4038/jnsfsr.v27i1.2974/ https://doi.org/10.4038/jnsfsr.v27i1.2974

[20] Fan, L., Pan, H., Soccol, A.T., Pandey, A. and Soccol, C.R. (2006) Advances in Mushroom Research in the Last Decade. Food Technology and Biotechnology, 44, 303-311. http://www.ftb.com.hr/images/pdfarticles/2006/July-September/44-303.pdf

[21] Gnaneswaran, S. and Wijayagunesakara, N.P. (1999) Survey and Identification of Insects Pests of Oyster Mushroom (Pleurotus ostreatus) Culture in Central Province of Sri Lanka. Tropical Agricultural Research and Extension, 2, 21-25. http://www.agri.ruh.ac.lk/tare/pdf/V_2.1/AG.2.2.7.pdf

[22] Wijewardena, J.D.H. (1993) Effect of Organic and Chemical Fertilizers on Vegetable Cultivation in Up-Country Intermediate Zone. Tropical Agriculturist, 149, 1-11

[23] Jayalal, R.G.U. and Adikaram, N.K.B. (2007) Influence of Trichoderma harzianum Metabolites on the Development of Green Mould Disease in the Oyster Mushroom. Ceylon Journal of Science (Biological Sciences), 36, 53-60.

https://www.researchgate.net/publication/236341255_Influence_of_Trichoderma_harzi anum_metabolites_on_the_development_of_green_mould_disease_in_the_Oyster_mu shroom

[24] Jayathunge, L. and Illeperuma, C. (2005) Extension of Postharvest Life of Oyster Mushroom by Modified Atmosphere Packaging Technique. Journal of Food Science, 70, 573. https://doi.org/10.1111/j.1365-2621.2005.tb08321.x

[25] Tano, K., Arul, J., Doyon, G. and Castaigne, F. (1999) Atmospheric Composition and Quality of Fresh Mushrooms in Modified Atmosphere Packages as Affected by Storage Temperature Abuse. Journal of Food Science, 64, 1073-1077. https://doi.org/10.1111/j.1365-2621.1999.tb12285.x 